\title{
Implications of Cellular Aging in Cardiac Reprogramming
}

\author{
Fabiana Passaro ${ }^{1}$ and Gianluca Testa ${ }^{2,3 *}$ \\ ${ }^{1}$ Department of Molecular Medicine and Medical Biotechnology, University of Naples "Federico II", Napoli, Italy, \\ ${ }^{2}$ Interdepartmental Center for Nanotechnology Research - NanoBem, University of Molise, Campobasso, Italy, ${ }^{3}$ Department \\ of Medicine and Health Sciences "Vincenzo Tiberio", University of Molise, Campobasso, Italy
}

OPEN ACCESS

Edited by:

Gaia Spinetti,

MultiMedica (IRCCS), Italy

Reviewed by:

Lucio Barile,

Cardiocentro Ticino, Switzerland

Manuel M. Mazo,

Universidad de Navarra, Spain

*Correspondence:

Gianluca Testa

gianluca.testa@unimol.it

Specialty section:

This article was submitted to Cardiovascular Biologics and

Regenerative Medicine,

a section of the journal

Frontiers in Cardiovascular Medicine

Received: 08 February 2018

Accepted: 20 April 2018

Published: 27 April 2018

Citation:

Passaro F and Testa $G$ (2018) Implications of Cellular Aging in Cardiac Reprogramming.

Front. Cardiovasc. Med. 5:43. doi: 10.3389/fcvm.2018.00043
Aging is characterized by a chronic functional decline of organ systems which leads to tissue dysfunction over time, representing a risk factor for diseases development, including cardiovascular. The aging process occurring in the cardiovascular system involves heart and vessels at molecular and cellular level, with subsequent structural modifications and functional impairment. Several modifications involved in the aging process can be ascribed to cellular senescence, a biological response that limits the proliferation of damaged cells. In physiological conditions, the mechanism of cellular senescence is involved in regulation of tissue homeostasis, remodeling, and repair. However, in some conditions senescence-driven tissue repair may fail, leading to the tissue accumulation of senescent cells which in turn may contribute to tumor promotion, aging, and age-related diseases. Cellular reprogramming processes can reverse several age-associated cell features, such as telomere length, DNA methylation, histone modifications and cell-cycle arrest. As such, induced Pluripotent Stem Cells (iPSCs) can provide models of progeroid and physiologically aged cells to gain insight into the pathogenesis of such conditions, to drive the development of new therapies for premature aging and to further explore the possibility of rejuvenating aged cells. An emerging picture is that the tissue remodeling role of cellular senescence could also be crucial for the outcomes of in vivo reprogramming processes. Experimental evidence has demonstrated that, on one hand, senescence represents a cell-autonomous barrier for a cell candidate to reprogramming, but, on the other hand, it may positively sustain the reprogramming capability of surrounding cells to generate fully proficient tissues. This review fits into this conceptual framework by highlighting the most prominent concepts that characterize aging and reprogramming and discusses how the aging tissue might provide a favorable microenvironment for in vivo cardiac reprogramming.

Keywords: cellular senescence, SASP, reprogramming of somatic cells, cardiovascular aging, direct cardiac reprogramming

\section{INTRODUCTION}

In the last decades, developed countries have faced a significant rise in life expectancy with consistent dramatic increase of the elderly population (1).

Aging is the major risk factor for cardiovascular diseases, which are the leading cause of morbidity, disability, and death in western countries (2). 
The aging process occurring in the cardiovascular system involves heart and vessels at molecular and cellular level with consequent structural modifications and functional impairment (3).

Cardiac aging involves on one hand, cellular macromolecular and mitochondrial and energetic changes and, on the other hand, cell renewal mechanisms and stem cell function. In addition, also extracellular matrix (ECM) alterations contribute to the structural changes that ultimately lead to cardiac dysfunction commonly observed in the elderly (4).

Several modifications involved in the process of cardiac aging can be ascribed to cellular senescence (3). A role for cellular senescence has been hypothesized in the development of cardiovascular diseases which are frequently associated with aging, like atherosclerosis and heart failure. The activation of the cellular senescence genetic program prompts a series of molecular changes, mostly affecting cell cycle, ECM, secretion of growth factors, and inflammatory mediators. Moreover, cellular senescence has been demonstrated crucial for the homeostasis of stem cell reservoir, thus pointing to its key role in tissue remodeling, both in physiological and pathological conditions (5).

In the attempt to regenerate functional cardiomyocytes (CMs), different approaches have been developed in recent decades, ranging from the stimulation of the intrinsic proliferative capacity of resident CMs to the enhancement of resident or not resident (tissue grafts) cardiac progenitor cells differentiation (6-9).

The discovery of induced Pluripotent Stem Cells (iPSCs) by Takahashi and Yamanaka in 2006 (10) has changed the field of cardiac regenerative medicine, unveiling a new approach to heart regeneration. Since then, either the cardiac differentiation of iPSCs or the conversion of one differentiated cell type into another, without proceeding through a pluripotent intermediate, the so-called "direct reprogramming", was reported for different cell types including CMs (11).

\section{Reprogramming Processes in the Aging Contest}

The manipulation of cell fates through reprogramming has deeply changed the established concepts about the stability of cellular identity, leading to new fields of research in human disease modeling, in vitro tissue differentiation and cellular transdifferentiation (12).

Since 2006, when Takahashi and Yamanaka (10) announced the successful derivation of iPSCs from adult mouse fibroblasts through the ectopic co-expression of the four genes OCT4, SOX2, KLF4 and c-MYC (OSKM), further studies reported of successful reprogramming of a wide variety of other human cell types (13-15). These results demonstrated the apparently universal capacity to alter cellular identity.

As iPSCs maintain the key features of ES cells, including the ability to give rise to any cell type within the body, this technology paved the way to innovative cell replacement therapies. However, transplantation of iPSC-derived cells raises several safety concerns. For instance, iPSC-derived cardiomyocytes frequently display different electrophysiological characteristics and immature functionality, making these cells unsuitable for transplantation (16).

In general, clinical application of this in vitro technology is a challenge, as in vitro manipulation of cells still brings up concerns on cell contamination and accumulation of mutations, transplantation procedures, delivery strategies and retention of the graft.

Regarding aging and age-related disorders, several experimental evidence demonstrated that, even though aging is a barrier to reprogramming, an aged cell may still be reprogrammed (17). Thus, iPSCs may provide models of progeroid and physiologically aged cells to gain insight into the pathogenesis of such conditions, to develop new therapies for premature aging and to further explore the possibility of rejuvenating aged cells.

Nevertheless, the latter may also represent a major problem of modeling aging with iPSCs as, once reprogrammed, aged cells no longer display age-associated characteristics such as telomere shortening, reduced mitochondrial fitness, and cellular senescence (18-21). This situation hampers the use of rejuvenating cells for the study of late-onset alterations, making it necessary to expose such cells to treatments inducing age- and stress-related conditions.

As aging constitutes a critical barrier to cell reprogramming, in aged cells it might be helpful to counteract some age-associated characteristics to increase reprogramming efficiency $(18,19$, 22-24). Among age-related alterations, cellular senescence seems to negatively impact the reprogramming process (25).

\section{Cellular Senescence as a Tissue- Remodeling Mechanism}

Cellular senescence was first described in 1961 by Hayflick and Moorhead (26) as a process that reduced the proliferation of normal human cells in culture. Interestingly, they also argued that senescence could have a pivotal role in driving the aging process in vivo. In the last decades, in vitro and in vivo evidence have contributed to defining senescence as an irreversible cell cycle arrest occurring when a proliferating cell is exposed to a severe genotoxic stress, thus revealing a multifaceted phenomenon combining both genetic and environmental components, which operate through convergent pathways $(27,28)$.

Today we know that this phenomenon described by Hayflick and Moorhead accounts for the so-called "replicative senescence" (RS), which refers to the irreversible cell cycle arrest due to the progressive telomeres attrition at each $S$ phase (29), and that occurs after extensive proliferation in the absence of endogenous telomerase activity (30-32). Apart from embryonic stem cells (33), which express telomerase, in principle, all proliferating cells can undergo RS (27).

From a molecular point of view, cell senescence is believed to have evolved as a mechanism aimed at the prevention of the replication and transmission of damaged DNA to future generations of cells, thus playing a role in the orchestration of tissue remodeling and repair, and acting as a tumor suppressor mechanism (5). In this sense, it is not surprising that cellular senescence has been also implicated in embryonic development, both in mice and humans (34).

However, regardless of their inability to replicate, senescent cells are still metabolically active. In particular, they develop an 
aberrant gene expression profile leading to the over-expression of different proteins, mostly secreted and not expressed by the young counterpart, which confers a proinflammatory behavior, the so-called Senescence-Associated Secretory Phenotype (SASP), able to induce or accelerate changes in surrounding normal tissues (35).

In general, senescent cells are efficiently cleared by phagocytosis, but, in some conditions, tissue repair may fail, leading to senescent cells accumulation in tissues, which in turn may contribute to tumor promotion, tissue aging and age-related diseases $(5,27,28)$.

The SASP comprises the secretion of chemokines, proinflammatory cytokines (with a particularly relevant role for interleukin-6 (IL-6) and interleukin-8 (IL-8)), growth factors and proteases (36-38), whose secretion triggers inflammation, which is critical for macrophages chemoattraction and the subsequent clearance of senescent cells by phagocytosis $(39,40)$. Nevertheless, SASP components may also induce senescence in surrounding cells in a paracrine manner, through a mechanism involving Reactive Oxygen Species (ROS) generation and DNA damage (41, 42). Recently, a role for SASP in inducing somatic stem/progenitor characteristics in several tissues has also been described (43).

Besides SASP, other peculiar characteristics of senescent cells are: the appearance of senescence-associated heterochromatin foci (SAHF), the expression of Senescence-Associated $\beta$-galactosidase (SA- $\beta$-gal), enlarged and flattened morphology, the presence of senescence-associated DNA-damage foci (SDFs) $(44,45)$.

Different stimuli, other than telomere erosion, may induce senescence (5). A common feature of such senescence-inducing stimuli is to elicit epigenomic disruption and genomic damage with the DNA damage response (DDR) activation, responsible for initiation and maintenance of both the in vitro and in vivo senescence growth arrest in mouse and human cells (46). These stimuli converge on activation of p53 and of cyclin-dependent kinase (CDK) inhibitors p16INK4A, p14ARF, p21CIP1 and p27 $(47,48)$. CDK-cyclin complexes inhibition leads to hypophosphorylation of the Retinoblastoma protein $(\mathrm{Rb})$, with the subsequent proliferation arrest (49).

Other stimuli triggering persistent DDR signaling, such as oncogene-driven mitogenic signals or over-expression of proproliferative genes that cause defective replication origins and replication fork collapse, also leads to a senescence growth arrest, the so-called "oncogene-induced senescence" (OIS) (50-52). Also, treatments with cytotoxic chemotherapeutic agents, such as etoposide, or de-regulation of some microRNA that break DNA double strand, may be responsible for a p53-dependent premature senescence (53-55). Senescence can also occur, however, without detectable DDR signaling. This "stress-induced senescence" (SIS) could be dependent on several endogenous or exogenous sources of stress, such as ROS $(56,57)$.

More recently, the role of cellular senescence in tissue remodeling has been linked to cellular reprogramming processes (18).

It is well established that cell senescence causes a p53dependent block to reprogramming (22-25). Indeed, improved reprogramming efficiency has been achieved by the knockingdown expression of p53, p21CIP1, p16INK4A and p14ARF (25, 58, 59), and microRNA-195 (60).

The transgenic expression of the four Yamanaka factors (OSKM) (10) in adult mice, in addition to reprogramming, also induces cellular damage and senescence, both in vitro (25) and in vivo (61, $62)$. These two opposite cellular fates are detectable in different subsets of cells, albeit in the same tissue $(61,62)$.

These results support the idea that cellular senescence may influence the outcome of cell-fate manipulating procedure in two ways: on the one hand it represents a cell-autonomous barrier for a cell candidate to reprogramming, but, on the other hand, it may positively sustain the reprogramming capability of surrounding cells to generate fully proficient tissues. Therefore, the emerging picture is that senescence, via SASPs, may generate a tissue microenvironment sustaining in vivo reprogramming (63).

\section{Cellular Senescence: A Cell-Autonomous Barrier for Reprogramming}

The number of senescent cells increases in organs during aging $(45,48)$. Consequently, old age donor cells may contain a more significant number of senescent and pre-senescent cells, and these would ultimately affect the reprogramming efficiency.

Moreover, the reprogramming process itself triggers senescence, the so-called reprogramming-induced senescence (RIS) $(25,62)$. Cells from old donors may, therefore, be more sensitive to RIS and more difficult to reprogram, due to the already activated intrinsic senescence pathways.

Studies investigating the possible influence of senescence on reprogramming highlighted a negative association between replicative passages of cultured cells and reprogramming efficiency, with a prominent role of $\mathrm{p} 16 / \mathrm{p} 21$-dependent senescence response in thwarting aging cell-fate manipulations (25), and, thus, confirming the complex role played by the Ink4a/Arf locus in reprogramming $(58,62)$

Pioneer studies aimed at investigating the effect of donor age on reprogramming efficiency were performed in mice and revealed that the older the donor mouse, the lower the extent of reprogramming efficiency (64-66). Indeed, a significant reduction was observed in the reprogramming efficiency of aged vs. young mouse dermal fibroblasts or bone marrow cells, in which those from older animals showed either lower or slower reprogramming (64-66). Nevertheless, these studies also demonstrated that, once iPSCs were obtained from these old donors, they have unchanged potential to be differentiated in vitro and in vivo.

Therefore, even if we can consider that aging may interfere with the onset of the reprogramming process in a cell-autonomous fashion, once the process starts it proceeds to completion until the development of iPSCs.

Contrary to mice, in humans, the aging process does not seem to impair the ability of cells to reprogram. Indeed, several groups generated iPSC lines, which expressed pluripotency markers, were able to differentiate into the three germ layers and to induce teratomas when injected into nude mice, from tissues of older individuals $(67,68)$, thus demonstrating that reprogramming to iPSC is possible regardless of the donor age. Also, the gene expression profile of these cells confirmed they had been reset to an embryonic-like stage $(19,58,64,67)$.

Lapasset et al. (19) tested the reprogramming feasibility of extreme aging phenotypes, generating iPSCs from post-mitotic cells and fibroblasts isolated from a 101 years old subject. Since 
then, the generation of iPSC from different centenarian tissue types was obtained (69-71). Interestingly, these iPSC obtained from centenarian fibroblasts were pluripotent and were able to generate all the three embryonic lineages.

The reprogramming process can reverse several age-associated cell features, such as cell-cycle arrest (25), DNA methylation and histone modifications (72), telomere length (73) and expression of pro-inflammatory factors (22).

Indeed, in iPSC the re-expression of telomerase (74), the modification of histone pattern (75) and the improvement of mitochondrial activity with increased energetic output and ROS resistance (76) have been demonstrated.

Hence, reprogramming somatic cells to iPSCs has been shown to reverses their "developmental clock", restoring it to levels similar to human embryonic stem cells (20). It can be argued that cellular age and identity are not unalterable endpoints, but merely plastic cellular states, mostly depending on the epigenetic code expressed at a given time, whose change is responsible of the whole reprogramming process.

\section{Cellular Senescence: A Booster for in Vivo Reprogramming}

Few studies explored the molecular and cellular contexts affecting in vivo reprogramming. Emerging evidence highlight a robust positive association between reprogramming and cellular senescence, which seems to create a tissue microenvironment favoring OSKM-driven reprogramming in neighboring cells.

It is well established that cellular damages associated to reprogramming activate the tumor suppressor genes p53, p21CIP1, p16INK4, and p14ARF, which result in proliferation arrest and, consequently, act as cell-autonomous barriers for cellular reprogramming $(22,24,58,76)$.

Mosteiro etal., in 2016 showed for the first time that the expression of Yamanaka factors in vivo not only starts the reprogramming process on some cells but also imposes exacerbated DNA damage on many other cells, leading them toward a senescence state (62).

These reprogramming-induced senescent cells facilitate in vivo reprogramming through the paracrine action of some SASP components, in particular, IL-6 $(61,62,77)$. Authors demonstrated that OSKM transduction, in the absence of p53, leads to extensive damage and RIS in tissues, resulting in high levels of secreted IL-6 which further enhance reprogramming. On the contrary, in the absence of Ink4a/Arf, RIS is severely compromised, with low IL-6 secretion levels. Although the Ink4a/Arf deficiency should represent a cell-autonomous advantage to reprogramming, the results obtained exhibit a very inefficient reprogramming process, probably due to the in vivo absence of RIS and IL-6 secretion $(62,77)$.

This also might be observed in the reprogramming of aged or injured tissues, where the accumulation of senescent cells may increase OSKM reprogramming by sending signals to surrounding cells. As it has been demonstrated that SASP may also induce somatic stem/progenitor characteristics in several tissues (43), a fascinating picture could be the identification of such a signal capable of inducing tissue regeneration to promote tissue repair.

Possible effects of cellular senescence on the reprogramming process are schematically depicted in Figure 1.

\section{Cellular Senescence in the Heart}

Despite the fact that heart has been traditionally considered a postmitotic organ, in the recent decades the growth of the cardiovascular research field has led to the hypothesis that the heart can retain a regenerative potential (78), even if limited and still not therapeutically exploitable. Senescence can be described as the irreversible cell-cycle arrest that occurs in mitotic cells; thus, it can seem inappropriate to consider senescence in a context, cardiac, in which cell replication is quite limited. Nevertheless, hallmarks of senescence can be found in the aging heart and recently it has been shown that an increase in senescence markers in the cardiovascular system such as cardiac tissue, great vessels, and pericardium is associated with increased dysfunction and reduced lifespan (79). Thus, in the light of cardiovascular regeneration, cardiac senescence can be considered as organ senescence and analyzed in both cardiomyocytes and noncardiomyocytes. Cardiac senescence is characterized by the decrease in the number of cardiomyocytes and their increased size, with age and cardiovascular diseases, which represent a fundamental characteristic of cardiac remodeling, along with extracellular matrix increase (80). The numerical changes that occur with aging are mainly due to the age-associated reduced efficiency of autophagy (81).

Telomere length is another hallmark of aging and has been associated with cardiovascular disease development and mortality in elderly patients (82). However, the causality of these associations remains uncertain (83).

Other crucial aspects associated with cardiomyocyte senescence involve age-dependent defects of adrenergic signaling and calcium handling. These two cellular alterations are typically affected by age. Increased norepinephrine circulating levels are the results of reduced plasma clearance and increased spillover from the tissues (82). These alterations lead to the progressive impairment of adrenergic responsiveness, with the consequent $\beta$-adrenergic desensitization typically observed in cardiovascular aging. The dysfunction of the myocardial sarcoplasmic reticulum calcium adenosine triphosphatase (SERCA2a) is responsible for the impairment in calcium handling observed in cardiomyocyte aging (84).

Mitochondrial inability to maintain ROS homeostasis contributes to the accumulation of highly reactive products, which increases DNA mutations, inflammation, and cell death pathways activation ultimately leading to cellular senescence (85). Also, the family of nicotinamide adenine dinucleotide-dependent deacetylases termed sirtuins have an established role in human aging (86) and are related to cardiovascular aging and disease development (87).

Non-cardiomyocytes represent the vast majority of cardiac cells population. In particular, cardiac fibroblasts represent the main contributors to the cardiac structure through the production, maintenance, and remodeling of extracellular matrix. Fibroblasts isolated from aged hearts show impaired proliferative capacity and are less responsive to profibrotic stimuli in vitro (87). Infarcted aged hearts showed a reduction of collagen deposition in the scar, a delay in the scar stabilization, and reduced yet prolonged inflammation, highlighting a possible age-related cardiac fibroblasts dysfunction (88). In addition to the cellular changes, aging is associated with overexpression of several ECM proteins, such as collagen, fibronectin, and alpha 1 and alpha 5 integrin along with increased collagen cross-linking $(89,90)$. 


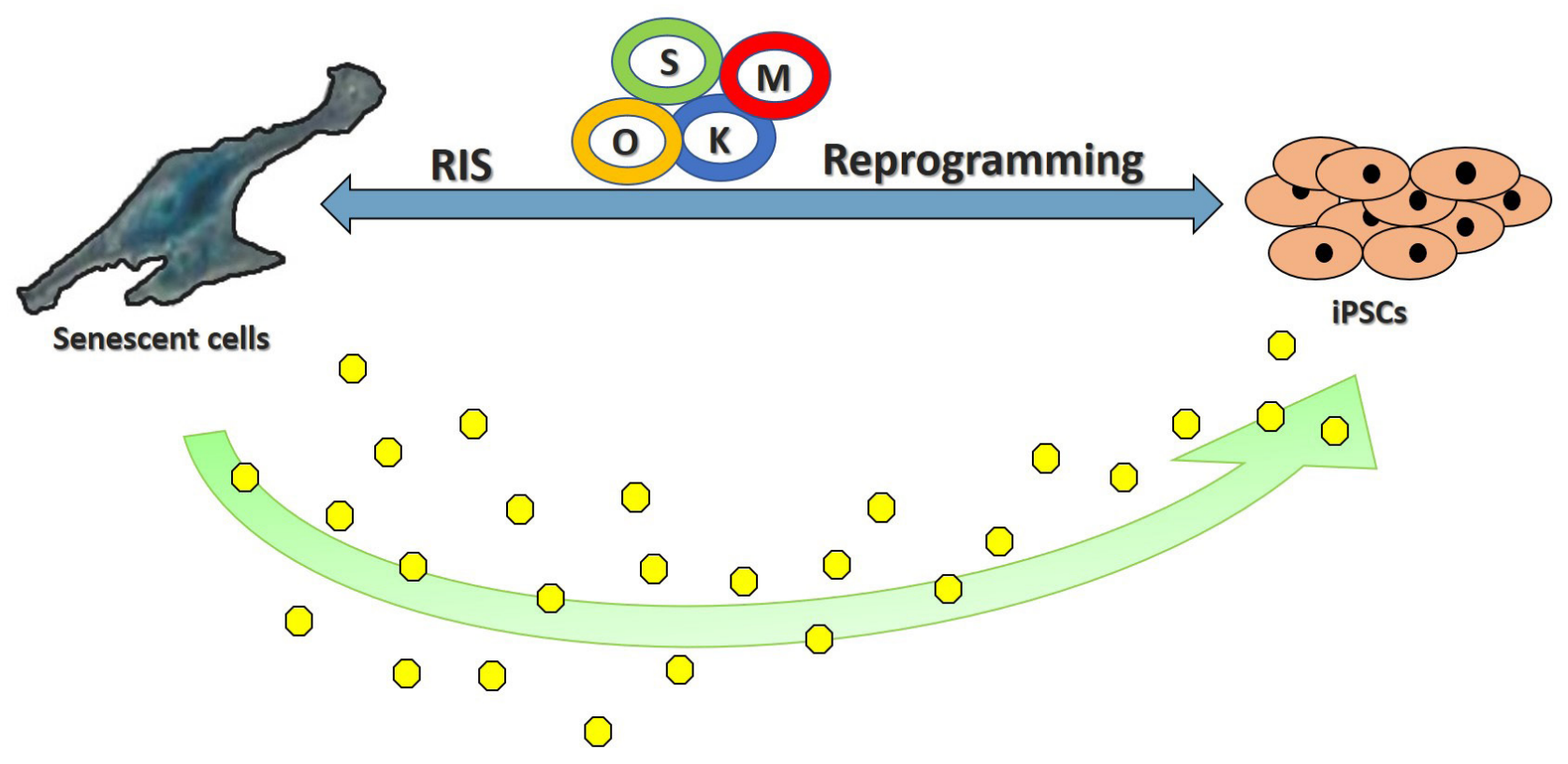

SASP

FIGURE 1 | Schematic representation of possible implications of cellular senescence on the reprogramming process. RIS, Reprogramming Induced Senescence; O, Oct4; K, Klf4; S, Sox2; M, c-Myc; SASP, Senescence-Associated Secretory Phenotype.

\section{Reprogramming the Aging Heart}

Although high cellular plasticity is associated with high regenerative capacity, it also bears high tumorigenicity. Thus, mechanisms aimed at the increase of cellular plasticity may be a double-edged sword. This and other concerns, such as the failure to demonstrate that iPSCs-derived cardiomyocytes, once transplanted, may improve cardiac function, suggest caution in the adoption of such a therapeutic strategy.

Hence, the possibility of remuscularizing an aged or damaged human heart with such approach highlights some critical questions that need to be addressed before in vitro-derived cardiomyocyte transplantation can become part of a regenerative therapy.

In recent years it has been developed an alternative method to produce cardiomyocytes in vitro as well as in vivo, the so-called "direct cardiac reprogramming". This method bypasses the concerns on plasticity and relative tumorigenicity, as it involves a cell fate switch from a fully differentiated cell type into another, without going through the pluripotent state.

The direct conversion was achieved for the first time in 2010 by forcing expression of tree key lineage-specific factors: Gata4, Mef2c, and Tbx5 (GMT factors) in mice (91).

Since then, different research groups worldwide reported unique combinations of transcription factors, microRNAs and/ or chemical compounds capable of engineering mouse and human fibroblasts cell fate to produce cardiomyocyte-like cells both in vitro and in vivo (92-95 and extensively reviewed in 11). This is a new hope to restore heart function and induce regeneration.
Indeed, several elegant efforts have been made to induce heart regeneration by direct reprogramming of cardiac fibroblasts of the infarcted area into induced cardiomyocytes (iCMs). Interestingly, findings revealed that in situ trans-differentiation of cardiac fibroblasts into iCMs results in functional improvements in mouse models of MI, yielding more mature cardiomyocytes with more similarity to their endogenous counterparts than in the in vitro setting $(92,96-99)$. These data suggest that cardiac microenvironment may specifically have a positive imp act on the robustness of the process rather than environments of other tissues or in vitro conditions.

Interestingly, supporting the positive role of the cardiac milieu, it has been presented that the infarcted adult heart induced more cardiomyocyte maturation and hypertrophy than the neonatal heart (92). This proves that in vivo environment of the infarcted ventricle can provide inductive signals specifically for the threelineage cardiovascular differentiation of iPSCs and maturation of injected cardiomyocytes.

Identification of such powerful inducers in cardiac microenvironment could provide new insights into the mechanisms of cardiac reprogramming. Moreover, other neighboring cell types can make the heart tissue more permissive and favorable to reprogramming.

Indeed, the SASP is characterized by the increase of several soluble factors, either proteins or nonproteins, many of which may play a role in promoting and facilitating tissue reprogramming. 
Recently, this topic has become the object of more deep investigations, several of which have led to very interesting yet non-conclusive results.

Recently, intriguing results have been obtained in non-cardiac tissues, such as skeletal muscle and pancreas (61, 62). Mosteiro et al., starting from the evidence that the in vivo transduction of OKSM factors induces cellular damage and senescence along with dedifferentiation (62), found a possible role for SASP components in in vivo cell reprogramming (77). Also in skeletal muscle, it has been demonstrated that in-vivo reprogramming is facilitated by the accumulation of senescent cells (61). These results strongly suggest that cell intrinsic and extrinsic effects of senescence can be pivotal for tissue repair and regeneration, particularly during the aging process and in the presence of tissue damage. Indeed, tissue injury enhances the in-vivo lineage reprogramming efficiency in both liver and pancreas and the induction of a senescent program could drive these processes.

With aging, several of the SASP components, particularly those related to proinflammatory signaling, have been shown to be involved in tissue remodeling in both the heart and large arteries. As previously highlighted, a possible interesting role in the remodeling process of the cardiovascular system can be played by IL-6. IL-6, in fact, is significantly increased, secreted and up-regulated in aged Vascular Smooth Muscle Cells (VSMCs) as well as in aged myocardium (100).

To our knowledge, no data on cardiac direct reprogramming and SASP are available.

At cardiac level, in particular, an age-associated increase in myocardial damaged and matrix remodeling seems to be promoted by up-regulation of this cytokine, along with TNF-alpha and both seem to be required for myocardial development (100-102). The role of IL-6, more specifically, seems to be central in the process of myocardial remodeling, either pathological or physiological. In fact, while on the one hand it has recently been showed that deletion of IL-6 attenuates pressure overload-induced left ventricular remodelling, on the other hand, deletion of IL-6 has been demonstrated to be responsible for left ventricular dysfunction, fibrosis, reduced capillary density, and significant alteration of cell populations of the developing and adult heart. Both these pathological and developmental responses to IL-6 signaling occur through the modulation of the activity of STAT3 (103).

IL-6 is also able to enhance in vitro reprogramming, by replacing the activity of another IL- 6 cytokine family member, the leukemia inhibitory factor (LIF), a related cytokine often used for reprogramming in vitro $(103,104)$.

\section{REFERENCES}

1. Christensen K, Doblhammer G, Rau R, Vaupel JW. Ageing populations: the challenges ahead. Lancet (2009) 374(9696):1196-208. doi: 10.1016/S01406736(09)61460-4

2. Heidenreich PA, Trogdon JG, Khavjou OA, Butler J, Dracup K, Ezekowitz MD, et al. Forecasting the future of cardiovascular disease in the United States: a policy statement from the American Heart Association. Circulation (2011) 123(8):933-44. doi: 10.1161/CIR.0b013e31820a55f5
Given the growing evidence on a possible role of IL-6 in facilitating in vitro reprogramming and given the increased levels of this cytokine in the aged heart, it can be argued that also an in-vivo direct cardiac reprogramming process could be favorably influenced in the presence of IL-6.

LIF is an essential compound used during the induced cardiomyocytes maturation in the direct cardiac reprogramming process (105). Like IL-6, also LIF acts through a shared gp130 receptor leading to overlapping but characteristic biological actions mediated by the activation of STAT3 (106). Several studies have been performed on the intracellular signals leading to the formation of a "wall of protection" against cardiomyocytes acute stress (104). LIF would seem to have other effects on other cell types in the infarcted myocardium reparative process. In mouse infarcted myocardium, LIF has been shown to contribute to the homing process of bone marrow-derived cardiac progenitors, along with the differentiation of resident cardiac stem cells into endothelial cells $(106,107)$. Increased circulating LIF in a mouse model of MI not only were protective against cardiomyocyte death but was able to enhance neovascularization and to induce bone marrow cells homing in the heart and their differentiation into cardiomyocytes (108).

\section{CONCLUSIONS}

In vivo lineage reprogramming-based therapies are being considered to treat a wide range of diseases, and tissue-damageinduced senescence seems to contribute to in vivo cellular plasticity via SASP positively. Although this beneficial role for cellular senescence has been demonstrated on muscle and pancreas regeneration, no data are available for a similar effect on cardiac regeneration. Nevertheless, experimental evidence has shown that the reprogramming by GMT in the infarcted adult heart induced more cardiomyocyte maturation and hypertrophy than into the neonatal heart. It may be speculated that this could be ascribed to the induction of a senescence program in the damaged myocardium, thus supporting the positive contribution of the cardiac milieu to the in vivo reprogramming process. Hence, it will be of great interest to investigate how specific SASP components would also affect cardiac reprogramming.

\section{AUTHOR CONTRIBUTIONS}

The authors conceived and wrote the manuscript equally.

3. Paneni F, Diaz Cañestro C, Libby P, Lüscher F, Camici GG. The Aging Cardiovascular System: Understanding It at the Cellular and Clinical Levels. J Am Coll Cardiol (2017) 69(15):1952-67.

4. Iop L, dal Sasso E, Schirone L, Forte M, Peruzzi M, Cavarretta E, et al. The Light and Shadow of Senescence and Inflammation in Cardiovascular Pathology and Regenerative Medicine. Mediators Inflamm. (2017) 2017:7953486-. doi: $10.1155 / 2017 / 7953486$

5. Muñoz-Espín D, Serrano M. Cellular senescence: from physiology to pathology. Nat Rev Mol Cell Biol (2014) 15(7):482-96. doi: 10.1038/nrm3823 
6. Tang YL, Wang YJ, Chen LJ, Pan YH, Zhang L, Weintraub NL. Cardiac-derived stem cell-based therapy for heart failure: progress and clinical applications. Exp Biol Med (2013) 238(3):294-300. doi: 10.1177/1535370213477982

7. Jansen Of Lorkeers SJ, Eding JE, Vesterinen HM, van der Spoel TI, Sena ES, Duckers HJ, et al. Similar effect of autologous and allogeneic cell therapy for ischemic heart disease: systematic review and meta-analysis of large animal studies. Circ Res (2015) 116(1):80-6. doi: 10.1161/ CIRCRESAHA.116.304872

8. Chong JJH, Yang X, don CW, Minami E, Liu Y-W, Weyers JJ, et al. Human embryonic-stem-cell-derived cardiomyocytes regenerate non-human primate hearts. Nature (2014) 510(7504):273-7. doi: 10.1038/nature13233

9. Senyo SE, Lee RT, Kühn B. Cardiac regeneration based on mechanisms of cardiomyocyte proliferation and differentiation. Stem Cell Res (2014) 13(3):532-41. doi: 10.1016/j.scr.2014.09.003

10. Takahashi K, Yamanaka S. Induction of pluripotent stem cells from mouse embryonic and adult fibroblast cultures by defined factors. Cell (2006) 126(4):663-76. doi: 10.1016/j.cell.2006.07.024

11. Ebrahimi B. In vivo reprogramming for heart regeneration: A glance at efficiency, environmental impacts, challenges and future directions. J Mol Cell Cardiol (2017) 108:61-72. doi: 10.1016/j.yjmcc.2017.05.005

12. Jopling C. Boue S, and Izpisua Belmonte JC. Dedifferentiation, transdifferentiation and reprogramming: three routes to regeneration. Nat Rev Mol Cell Biol (2011) 12(2):79-89.

13. Takahashi K, Tanabe K, Ohnuki M, Narita M, Ichisaka T, Tomoda K, et al. Induction of pluripotent stem cells from adult human fibroblasts by defined factors. Cell (2007) 131(5):861-72. doi: 10.1016/j.cell.2007.11.019

14. Yu J, Vodyanik MA, Smuga-Otto K, Antosiewicz-Bourget J, Frane JL, Tian S, et al. Induced pluripotent stem cell lines derived from human somatic cells. Science (2007) 318(5858):1917-20. doi: 10.1126/science.1151526

15. Robinton DA, Daley GQ. The promise of induced pluripotent stem cells in research and therapy. Nature (2012) 481(7381):295-305. doi: 10.1038/ nature 10761

16. Priori SG, Napolitano C, di Pasquale E, Condorelli G. Induced pluripotent stem cell-derived cardiomyocytes in studies of inherited arrhythmias. J Clin Invest (2013) 123(1):84-91. doi: 10.1172/JCI62838

17. Soria-Valles C, López-Otín C. iPSCs: on the road to reprogramming aging. Trends Mol Med (2016) 22(8):713-24. doi: 10.1016/j.molmed.2016.05.010

18. Mahmoudi S, Brunet A. Aging and reprogramming: a two-way street. Curr Opin Cell Biol (2012) 24(6):744-56. doi: 10.1016/j.ceb.2012.10.004

19. Lapasset L, Milhavet O, Prieur A, Besnard E, Babled A, Ait-Hamou N, et al. Rejuvenating senescent and centenarian human cells by reprogramming through the pluripotent state. Genes Dev (2011) 25(21):2248-53. doi: 10.1101/ gad.173922.111

20. Rando TA, Chang HY, Aging CHY. rejuvenation, and epigenetic reprogramming: resetting the aging clock. Cell (2012) 148(1-2):46-57. doi: 10.1016/j.cell.2012.01.003

21. Ocampo A, Reddy P, Martinez-Redondo P, Platero-Luengo A, Hatanaka F, Hishida $T$, et al. In vivo amelioration of age-associated hallmarks by partial reprogramming. Cell (2016) 167(7):e12):1719-33. doi: 10.1016/j. cell.2016.11.052

22. Marión RM, Strati K, Li H, Murga M, Blanco R, Ortega S, et al. A p53-mediated DNA damage response limits reprogramming to ensure iPS cell genomic integrity. Nature (2009) 460(7259):1149-53. doi: 10.1038/nature08287

23. Marion RM, Strati K, Li H, Tejera A, Schoeftner S, Ortega S, et al. Telomeres acquire embryonic stem cell characteristics in induced pluripotent stem cells. Cell Stem Cell (2009) 4(2):141-54. doi: 10.1016/j.stem.2008.12.010

24. Kawamura T, Suzuki J, Wang YV, Menendez S, Morera LB, Raya A, et al. Linking the p53 tumour suppressor pathway to somatic cell reprogramming. Nature (2009) 460(7259):1140-4. doi: 10.1038/nature08311

25. Banito A, Rashid ST, Acosta JC, Li S, Pereira CF, Geti I, et al. Senescence impairs successful reprogramming to pluripotent stem cells. Genes Dev (2009) 23(18):2134-9. doi: 10.1101/gad.1811609

26. Hayflick L, Moorhead PS. The serial cultivation of human diploid cell strains. Exp Cell Res (1961) 25(3):585-621. doi: 10.1016/0014-4827(61)90192-6

27. Campisi J, D'Adda di Fagagna F. Cellular senescence: when bad things happen to good cells. Nat Rev Mol Cell Biol (2007) 8(9):729-40. doi: 10.1038/nrm2233

28. Collado M, Blasco MA, Serrano M. Cellular senescence in cancer and aging. Cell (2007) 130(2):223-33. doi: 10.1016/j.cell.2007.07.003
29. Harley CB, Futcher AB, Greider CW. Telomeres shorten during ageing of human fibroblasts. Nature (1990) 345(6274):458-60. doi: 10.1038/345458a0

30. Bodnar AGet al. Extension of life-span by introduction of telomerase into normal human cells. Science (1998) 279(5349):349-52. doi: 10.1126/ science.279.5349.349

31. van Deursen JM. The role of senescent cells in ageing. Nature (2014) 509(7501):439-46. doi: 10.1038/nature13193

32. Fumagalli M, Rossiello F, Clerici M, Barozzi S, Cittaro D, Kaplunov JM, et al. Telomeric DNA damage is irreparable and causes persistent DNAdamage-response activation. Nat Cell Biol (2012) 14(4):355-65. doi: $10.1038 / \mathrm{ncb} 2466$

33. Miura T, Mattson MP, Rao MS. Cellular lifespan and senescence signaling in embryonic stem cells. Aging Cell (2004) 3(6):333-43. doi: 10.1111/j.14749728.2004.00134.x

34. Davaapil H, Brockes JP, Yun MH. Conserved and novel functions of programmed cellular senescence during vertebrate development. Development (2017) 144(1):106-14. doi: 10.1242/dev.138222

35. Freund A, Orjalo AV, Desprez P-Y, Campisi J. Inflammatory networks during cellular senescence: causes and consequences. Trends Mol Med (2010) 16(5):238-46. doi: 10.1016/j.molmed.2010.03.003

36. Acosta JC, O'Loghlen A, Banito A, Guijarro MV, Augert A, Raguz S, et al. Chemokine signaling via the CXCR2 receptor reinforces senescence. Cell (2008) 133(6):1006-18. doi: 10.1016/j.cell.2008.03.038

37. Coppé J-P, Patil CK, Rodier F, Sun Y, Muñoz DP, Goldstein J, et al. Senescenceassociated secretory phenotypes reveal cell-nonautonomous functions of oncogenic RAS and the p53 tumor suppressor. PLoS Biol. (2008) 6(12):285368. doi: 10.1371/journal.pbio.0060301

38. Kuilman T, Michaloglou C, Vredeveld LCW, Douma S, van Doorn R, Desmet CJ, et al. Oncogene-induced senescence relayed by an interleukindependent inflammatory network. Cell (2008) 133(6):1019-31. doi: 10.1016/j. cell.2008.03.039

39. Xue W, Zender L, Miething C, Dickins RA, Hernando E, Krizhanovsky V, et al. Senescence and tumour clearance is triggered by p53 restoration in murine liver carcinomas. Nature (2007) 445(7128):656-60. doi: 10.1038/ nature 05529

40. Hoenicke L, Zender L. Immune surveillance of senescent cells-biological significance in cancer- and non-cancer pathologies. Carcinogenesis (2012) 33(6):1123-6. doi: 10.1093/carcin/bgs124

41. Acosta JC, Banito A, Wuestefeld T, Georgilis A, Janich P, Morton JP, et al. A complex secretory program orchestrated by the inflammasome controls paracrine senescence. Nat Cell Biol (2013) 15(8):978-90. doi: 10.1038/ncb2784

42. Nelson G, Wordsworth J, Wang C, Jurk D, Lawless C, Martin-Ruiz C, et al. A senescent cell bystander effect: senescence-induced senescence. Aging Cell (2012) 11(2):345-9. doi: 10.1111/j.1474-9726.2012.00795.x

43. Ritschka B, Storer M, Mas A, Heinzmann F, Ortells MC, Morton JP, et al. The senescence-associated secretory phenotype induces cellular plasticity and tissue regeneration. Genes Dev (2017) 31(2):172-83. doi: 10.1101/ gad.290635.116

44. Narita M, Nuñez S, Heard E, Narita M, Lin AW, Hearn SA, et al. Rb-mediated heterochromatin formation and silencing of E2F target genes during cellular senescence. Cell (2003) 113(6):703-16. doi: 10.1016/S0092-8674(03)00401-X

45. Dimri GP, Lee X, Basile G, Acosta M, Scott G, Roskelley C, et al. A biomarker that identifies senescent human cells in culture and in aging skin in vivo. Proc. Natl Acad. Sci. USA (1995) 92(20):9363-7. doi: 10.1073/pnas.92.20.9363

46. Rodier F, Coppé J-P, Patil CK, Hoeijmakers WAM, Muñoz DP, Raza SR, et al. Persistent DNA damage signalling triggers senescence-associated inflammatory cytokine secretion. Nat Cell Biol (2009) 11(8):973-9. doi: $10.1038 /$ ncb1909

47. Salama R, Sadaie M, Hoare M, Narita M. Cellular senescence and its effector programs. Genes Dev (2014) 28(2):99-114. doi: 10.1101/gad.235184.113

48. Kuilman T, Michaloglou C, Mooi WJ, Peeper DS. The essence of senescence. Genes Dev (2010) 24(22):2463-79. doi: 10.1101/gad.1971610

49. Chicas A, Wang X, Zhang C, Mccurrach M, Zhao Z, Mert O, et al. Dissecting the unique role of the retinoblastoma tumor suppressor during cellular senescence. Cancer Cell (2010) 17(4):376-87. doi: 10.1016/j.ccr.2010.01.023

50. Serrano M, Lin AW, Mccurrach ME, Beach D, Lowe SW. Oncogenic ras provokes premature cell senescence associated with accumulation of p53 and p16INK4a. Cell (1997) 88(5):593-602. doi: 10.1016/S0092-8674(00)81902-9 
51. Gorgoulis VG, Halazonetis TD. Oncogene-induced senescence: the bright and dark side of the response. Curr. Opin. Cell Biol. (2010) 22(6):816-27. doi: 10.1016/j.ceb.2010.07.013

52. Alimonti A, Nardella C, Chen Z, Clohessy JG, Carracedo A, Trotman LC, et al. A novel type of cellular senescence that can be enhanced in mouse models and human tumor xenografts to suppress prostate tumorigenesis. J Clin Invest (2010) 120(3):681-93. doi: 10.1172/JCI40535

53. Napolitano M, Comegna M, Succoio M, Leggiero E, Pastore L, Faraonio $\mathrm{R}$, et al. Comparative analysis of gene expression data reveals novel targets of senescence-associated microRNAs. PLoS ONE (2014) 9(6):e98669. doi: 10.1371/journal.pone.0098669

54. Faraonio R, Salerno P, Passaro F, Sedia C, Iaccio A, Bellelli R, et al. A set of miRNAs participates in the cellular senescence program in human diploid fibroblasts. Cell Death Differ (2012) 19(4):713-21. doi: 10.1038/cdd.2011.143

55. Comegna M, Succoio M, Napolitano M, Vitale M, D'Ambrosio C, Scaloni A, et al. Identification of miR-494 direct targets involved in senescence of human diploid fibroblasts. FASEB J (2014) 28(8):3720-33. doi: 10.1096/fj.13239129

56. Chen Q, Fischer A, Reagan JD, Yan LJ, Ames BN. Oxidative DNA damage and senescence of human diploid fibroblast cells. Proc. Natl Acad. Sci. USA (1995) 92(10):4337-41. doi: 10.1073/pnas.92.10.4337

57. Soutoglou E, Misteli T. Activation of the cellular DNA damage response in the absence of DNA lesions. Science (2008) 320(5882):1507-10. doi: 10.1126/ science. 1159051

58. Li H, Collado M, Villasante A, Strati K, Ortega S, Cañamero M, et al. The Ink4/Arf locus is a barrier for iPS cell reprogramming. Nature (2009) 460(7259):1136-9. doi: 10.1038/nature08290

59. Hong H, Takahashi K, Ichisaka T, Aoi T, Kanagawa O, Nakagawa M, et al. Suppression of induced pluripotent stem cell generation by the p53-p21 pathway. Nature (2009) 460(7259):1132-5. doi: 10.1038/nature08235

60. Kondo H, Kim HW, Wang L, Okada M, Paul C, Millard RW, et al. Blockade of senescence-associated microRNA-195 in aged skeletal muscle cells facilitates reprogramming to produce induced pluripotent stem cells. Aging Cell (2016) 15(1):56-66. doi: 10.1111/acel.12411

61. Chiche A, Le Roux I, von Joest M, Sakai H, Aguín SB, Cazin C, et al. Injuryinduced senescence enables in reprogramming in skeletal muscle. Cell Stem Cell (2017) 20(3):407-14. doi: 10.1016/j.stem.2016.11.020

62. Mosteiro L, Pantoja C, Alcazar N, Marión RM, Chondronasiou D, Rovira $\mathrm{M}$, et al. Tissue damage and senescence provide critical signals for cellular reprogramming in vivo. Science (2016) 354(6315):aaf4445. doi: 10.1126/ science.aaf 4445

63. Menendez JA, Alarcón T. Senescence-Inflammatory Regulation of Reparative Cellular Reprogramming in Aging and Cancer. Front Cell Dev Biol (2017) 5:49. doi: 10.3389/fcell.2017.00049

64. Wang B, Miyagoe-Suzuki Y, Yada E, Ito N, Nishiyama T, Nakamura M, et al. Reprogramming efficiency and quality of induced Pluripotent Stem Cells (iPSCs) generated from muscle-derived fibroblasts of mdx mice at different ages. PLoS Curr (2011) 3:RRN1274. doi: 10.1371/currents.RRN1274

65. Kim K, Doi A, Wen B, Ng K, Zhao R, Cahan P, et al. Epigenetic memory in induced pluripotent stem cells. Nature (2010) 467(7313):285-90. doi: 10.1038/ nature 09342

66. Cheng Z, Ito S, Nishio N, Xiao H, Zhang R, Suzuki H, et al. Establishment of induced pluripotent stem cells from aged mice using bone marrow-derived myeloid cells. J Mol Cell Biol (2011) 3(2):91-8. doi: 10.1093/jmcb/mjq044

67. Ohmine S, Squillace KA, Hartjes KA, Deeds MC, Armstrong AS, Thatava $\mathrm{T}$, et al. Reprogrammed keratinocytes from elderly type 2 diabetes patients suppress senescence genes to acquire induced pluripotency. Aging (2012) 4(1):60-73. doi: 10.18632/aging.100428

68. Chen H, Qian K, du Z, Cao J, Petersen A, Liu H, et al. Modeling ALS with iPSCs reveals that mutant SOD1 misregulates neurofilament balance in motor neurons. Cell Stem Cell (2014) 14(6):796-809. doi: 10.1016/j.stem.2014.02.004

69. Yagi T, Kosakai A, Ito D, Okada Y, Akamatsu W, Nihei Y, et al. Establishment of Induced Pluripotent Stem Cells from Centenarians for Neurodegenerative Disease Research. PLoS ONE (2012) 7(7):e41572. doi: 10.1371/journal.pone. 0041572

70. Lo Sardo V, Ferguson W, Erikson GA, Topol EJ, Baldwin KK, Torkamani A. Influence of donor age on induced pluripotent stem cells. Nat Biotechnol (2016) 35(1):69-74. doi: 10.1038/nbt.3749
71. Boulting GL, Kiskinis E, Croft GF, Amoroso MW, Oakley DH, Wainger BJ, et al. A functionally characterized test set of human induced pluripotent stem cells. Nat Biotechnol (2011) 29(3):279-86. doi: 10.1038/nbt.1783

72. Garinis GA, van der Horst GTJ, Vijg J, H.J. Hoeijmakers J. DNA damage and ageing: new-age ideas for an age-old problem. Nat Cell Biol (2008) 10(11):1241-7. doi: 10.1038/ncb1108-1241

73. Blasco MA. Telomere length, stem cells and aging. Nat Chem Biol (2007) 3(10):640-9. doi: 10.1038/nchembio.2007.38

74. Tat PA, Sumer H, Pralong D, Verma PJ. The efficiency of cell fusion-based reprogramming is affected by the somatic cell type and the in vitro age of somatic cells. Cell Reprogram (2011) 13(4):331-44. doi: 10.1089/cell.2011.0002

75. Utikal J, Polo JM, Stadtfeld M, Maherali N, Kulalert W, Walsh RM, et al. Immortalization eliminates a roadblock during cellular reprogramming into iPS cells. Nature (2009) 460(7259):1145-8. doi: 10.1038/nature08285

76. Prigione A, Fauler B, Lurz R, Lehrach H, Adjaye J. The senescence-related mitochondrial/oxidative stress pathway is repressed in human induced pluripotent stem cells. Stem Cells (2010) 28(4):721-33. doi: 10.1002/stem.404

77. Mosteiro L, Pantoja C, de Martino A, Serrano M. Senescence promotes in vivo reprogramming through p16(INK)(4a) and IL-6. Aging Cell (2017):e12711.

78. Anderson R, Richardson GD, Passos JF. Mechanisms driving the ageing heart. Exp Gerontol (2017) 5565(17):30464-3. doi: 10.1016/j.exger.2017.10.015

79. Baker DJ, Childs BG, Durik M, Wijers ME, Sieben CJ, Zhong J, et al. Naturally occurring p16Ink4a-positive cells shorten healthy lifespan. Nature (2016) 530(7589):184-9. doi: 10.1038/nature16932

80. Serrano M, Blasco Marı冈a A, Blasco MA. Putting the stress on senescence. Curr Opin Cell Biol (2001) 13(6):748-53. doi: 10.1016/S0955-0674(00)00278-

81. Shih H, Lee B, Lee RJ, Boyle AJ. The aging heart and post-infarction left ventricular remodeling. J Am Coll Cardiol (2011) 57(1):9-17. doi: 10.1016/j. jacc.2010.08.623

82. Laina A, Stellos K, Stamatelopoulos K. Vascular ageing: underlying mechanisms and clinical implications. Exp Gerontol (2017) 5565(17):30273-5. doi: 10.1016/j.exger.2017.06.007

83. Haycock PC, Heydon EE, Kaptoge S, Butterworth AS, Thompson A, Willeit P. Leucocyte telomere length and risk of cardiovascular disease: systematic review and meta-analysis. BMJ (2014) 349(jul08 3):g4227. doi: 10.1136/bmj. g4227

84. Kurz DJet al. Degenerative aortic valve stenosis, but not coronary disease, is associated with shorter telomere length in the elderly. Arterioscler Thromb Vasc Biol (2006) 26(6):e114-7. doi: 10.1161/01.ATV.0000222961.24912.69

85. Cosentino F, Francia P, Camici GG, Pelicci PG, Volpe M, Luscher TF. Final common molecular pathways of aging and cardiovascular disease: role of the p66Shc protein. Arterioscler Thromb Vasc Biol (2008) 28(4):622-8. doi: 10.1161/ATVBAHA.107.156059

86. Migliaccio E, Giorgio M, Mele S, Pelicci G, Reboldi P, Pandolfi PP, et al. The p66shc adaptor protein controls oxidative stress response and life span in mammals. Nature (1999) 402:309-13.

87. Camici GG, Savarese G, Akhmedov A, Lüscher TF. Molecular mechanism of endothelial and vascular aging: implications for cardiovascular disease. Eur Heart J (2015) 36(48):3392-403. doi: 10.1093/eurheartj/ehv587

88. Mattagajasingh I, Kim C-S, Naqvi A, Yamamori T, Hoffman TA, Jung S-B, et al. SIRT1 promotes endothelium-dependent vascular relaxation by activating endothelial nitric oxide synthase. Proc Natl Acad Sci USA (2007) 104(37):14855-60. doi: 10.1073/pnas.0704329104

89. Burgess ML, Mccrea JC, Hedrick HL. Age-associated changes in cardiac matrix and integrins. Mech Ageing Dev (2001) 122(15):1739-56. doi: 10.1016/ S0047-6374(01)00296-2

90. Minamino T, Miyauchi H, Yoshida T, Tateno K, Kunieda T, Komuro I. Vascular cell senescence and vascular aging. J Mol Cell Cardiol (2004) 36(2):175-83. doi: 10.1016/j.yjmcc.2003.11.010

91. Ieda M, Fu J-D, Delgado-Olguin P, Vedantham V, Hayashi Y, Bruneau BG, et al. Direct reprogramming of fibroblasts into functional cardiomyocytes by defined factors. Cell (2010) 142(3):375-86. doi: 10.1016/j.cell.2010.07.002

92. Qian L, Huang Y, Spencer CI, Foley A, Vedantham V, Liu L, et al. In vivo reprogramming of murine cardiac fibroblasts into induced cardiomyocytes. Nature (2012) 485(7400):593-8. doi: 10.1038/nature11044

93. Wada R, Muraoka N, Inagawa K, Yamakawa H, Miyamoto K, Sadahiro T, et al. Induction of human cardiomyocyte-like cells from fibroblasts by defined 
factors. Proc Natl Acad Sci USA (2013) 110(31):12667-72. doi: 10.1073/ pnas. 1304053110

94. Jd F, Stone NR, Liu L, Spencer CI, Qian L, Hayashi Y, et al. Direct reprogramming of human fibroblasts toward a cardiomyocyte-like state. Stem Cell Reports (2013) 1(3):235-47.

95. Nam Y-J, Song K, Luo X, Daniel E, Lambeth K, West K, et al. Reprogramming of human fibroblasts toward a cardiac fate. Proc Natl Acad Sci USA (2013) 110(14):5588-93. doi: 10.1073/pnas.1301019110

96. Song K, Nam Y-J, Luo X, Qi X, Tan W, Huang GN, et al. Heart repair by reprogramming non-myocytes with cardiac transcription factors. Nature (2012) 485(7400):599-604. doi: 10.1038/nature11139

97. Inagawa K, Miyamoto K, Yamakawa H, Muraoka N, Sadahiro T, Umei T, et al. Induction of cardiomyocyte-like cells in infarct hearts by gene transfer of Gata4, Mef2c, and Tbx5. Circ Res (2012) 111(9):1147-56. doi: 10.1161/ CIRCRESAHA.112.271148

98. Kadota S, Pabon L, Reinecke H, Murry CE. In Vivo maturation of human induced pluripotent stem cell-derived cardiomyocytes in neonatal and adult rat hearts. Stem Cell Rep (2017) 8(2):278-89. doi: 10.1016/j. stemcr.2016.10.009

99. Heinrich C, Spagnoli FM, Berninger B. In vivo reprogramming for tissue repair. Nat Cell Biol (2015) 17(3):204-11. doi: 10.1038/ncb3108

100. Kishimoto T. IL-6: from its discovery to clinical applications. Int Immunol (2010) 22(5):347-52. doi: 10.1093/intimm/dxq030

101. Sivasubramanian N, Coker ML, Kurrelmeyer KM, Maclellan WR, Demayo FJ, Spinale FG, et al. Left ventricular remodeling in transgenic mice with cardiac restricted overexpression of tumor necrosis factor. Circulation (2001) 104(7):826-31. doi: 10.1161/hc3401.093154

102. Cai D, Xaymardan M, Holm JM, Zheng J, Kizer JR, Edelberg JM. Ageassociated impairment in TNF-alpha cardioprotection from myocardial infarction. Am J Physiol Heart Circ Physiol (2003) 285(2):H463-9. doi: 10.1152/ajpheart.00144.2003
103. Brady JJ, Li M, Suthram S, Jiang H, Wong WH, Blau HM. Early role for IL-6 signalling during generation of induced pluripotent stem cells revealed by heterokaryon RNA-Seq. Nat Cell Biol (2013) 15(10):1244-52. doi: 10.1038/ ncb2835

104. Zouein FA, Kurdi M, Booz GW. LIF and the heart: just another brick in the wall? Eur Cytokine Netw (2013) 24(1):11-19. doi: 10.1684/ecn.2013.0335

105. Mohri T, Fujio Y, Obana M, Iwakura T, Matsuda K, Maeda M, et al. Signals through glycoprotein 130 regulate the endothelial differentiation of cardiac stem cells. Arterioscler. Thromb Vasc Biol (2009) 29(5):754-60. doi: 10.1161/ ATVBAHA.108.174870

106. Mohri T, Fujio Y, Maeda M, Ito T, Iwakura T, Oshima Y, et al. Leukemia inhibitory factor induces endothelial differentiation in cardiac stem cells. $J$ Biol Chem (2006) 281(10):6442-7. doi: 10.1074/jbc.M508969200

107. Iwakura T, Mohri T, Hamatani T, Obana M, Yamashita T, Maeda M, et al. STAT3/Pim-1 signaling pathway plays a crucial role in endothelial differentiation of cardiac resident Sca-1+ cells both in vitro and in vivo. J Mol Cell Cardiol (2011) 51(2):207-14. doi: 10.1016/j.yjmcc.2011.04.013

108. Zou Y, Takano H, Mizukami M, Akazawa H, Qin Y, Toko H, et al. Leukemia inhibitory factor enhances survival of cardiomyocytes and induces regeneration of myocardium after myocardial infarction. Circulation (2003) 108(6):748-53. doi: 10.1161/01.CIR.0000081773.76337.44

Conflict of Interest Statement: The authors declare that the research was conducted in the absence of any commercial or financial relationships that could be construed as a potential conflict of interest.

Copyright $\odot 2018$ Passaro and Testa. This is an open-access article distributed under the terms of the Creative Commons Attribution License (CC BY). The use, distribution or reproduction in other forums is permitted, provided the original author $(s)$ and the copyright owner are credited and that the original publication in this journal is cited, in accordance with accepted academic practice. No use, distribution or reproduction is permitted which does not comply with these terms. 